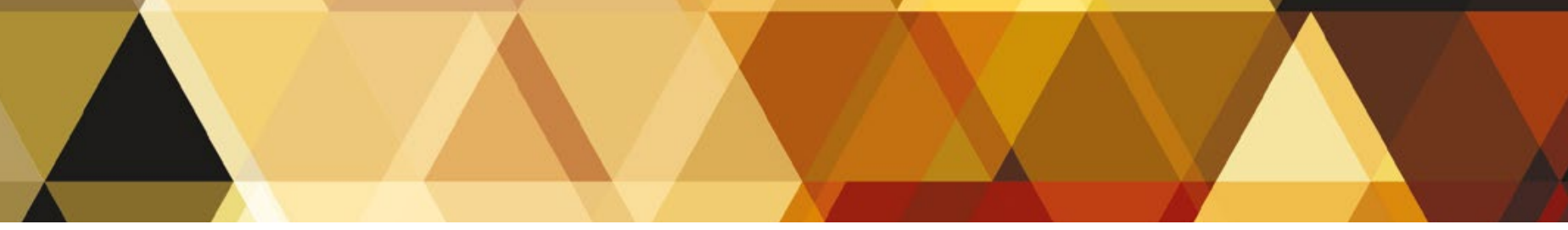

\title{
EM UMA ENCRUZILHADA E SEM UMA BÚSSOLA: UM PANORAMA DA EFICÁCIA E DOS DESAFIOS ENFRENTADOS PELA EDUCAÇÃO SECUNDÁRIA NA INGLATERRA
}

\section{AT A CROSSROADS AND WITHOUT A COMPASS: AN OVERVIEW OF THE EFFECTIVENESS AND CHALLENGES FACING SECONDARY EDUCATION IN ENGLAND}

EN UNA ENCRUCIJADA Y SIN BRÚJULA: UN PANORAMA SOBRE LA EFECTIVIDAD Y LOS DESAFÍOS DE LA EDUCACIÓN SECUNDARIA EN INGLATERRA

\section{Anthony McNamara*}

*Consultor Educacional e Liderança em Educação Secundária para a Diocese de Lancaster, Inglaterra.

E-mail: a.mcnamara2@sky.com

Recebido para publicação: 1.7.2018

Aprovado em: 17.7.2018

\section{Resumo}

Este panorama do ensino secundário na Inglaterra abrange aspectos como tipos de escolas, mudanças curriculares recentes e avaliação do progresso e aproveitamento do aluno. Ele descreve o impacto do Departamento de Normas para Educação, Serviços e Habilidades para Crianças (Office for Standards in Education, Children's Services and Skills - OFSTED) e a situação em relação ao recrutamento, progressão na carreira e retenção no ensino. Baseia-se em documentos governamentais e de pesquisa, além de lideranças interessadas, para mostrar por que o sistema é feito para ser fragmentado, sem direção, com baixo desempenho e acentuada desigualdade. A seção sobre o Brasil descreve os desafios e os pontos fortes de ambos os sistemas educacionais e a importância de investir na profissão docente.

Palavras-chave: Educação secundária. Baixo desempenho. Provisão pública. Liderança escolar. Mudanças no currículo. Avaliação. OFSTED. Profissão docente. Crise. Recrutamento. Retenção. Descontinuidade. Base Nacional Comum Curricular. OCDE. Melhores práticas.

\section{Abstract}

This overview of secondary education in England covers aspects of provision including types of schools, recent curriculum changes and assessment to student progress and attainment. It describes the impact of the Office for Standards in Education, 
Children's Services and Skills (OFSTED) and the situation regarding recruitment, career progression and retention in teaching. It draws on government and research documents, besides leading stakeholders, to show why the system is to be fragmented, directionless, underperforming and accentuating inequality. The section about Brazil outlines the challenges and strengths of both education systems and the importance of investing in the teaching profession.

Keywords: Secondary education. Underperformance. Public provision. School leadership. Curriculum changes. Assessment. OFSTED. Teaching profession. Crisis. Recruitment. Retention. Discontinuity. National Common Core Curriculum. OECD. Best practice.

\section{Resumen}

Este artículo sobre la educación secundaria en Inglaterra cubre aspectos de la provisión, tales como los tipos de escuelas, cambios curriculares recientes y la evaluación del progreso y los logros de los alumnos. Describe el impacto de la Oficina para Estándares en Educación, Servicios y Habilidades de los Niños (Office for Standards in Education, Children's Services and Skills - OFSTED) y la situación respecto del reclutamiento, el avance de la carrera y la retención en la enseñanza. Hace uso de documentos gubernamentales y de investigación, además de partes interesadas importantes, a fin de mostrar por qué el sistema tiende a ser fragmentado, sin dirección, posee un bajo rendimiento y acentúa la desigualdad. La sección sobre Brasil describe los desafíos y fortalezas de ambos sistemas educativos y la importancia de invertir en la profesión de la enseñanza.

Palabras clave: Educación Secundaria. Bajo rendimiento. Provisión Pública. Liderazgo Escolar. Cambios Curriculares. Evaluación. OFSTED. Profesión de la Enseñanza. Crisis. Reclutamiento. Retención. Discontinuidad. Currículo Nacional Común. OECD. Mejor práctica.

\section{Introdução}

Este panorama do ensino secundário público na Inglaterra começa com um retrato de como ele está se saindo quando comparado a outras jurisdições. Em seguida, analisa a estrutura da educação estatal na Inglaterra, sua atual provisão curricular secundária, como avalia os alunos e como responsabiliza as escolas. Descreve dificuldades relacionadas com o recrutamento e retenção de professores e dirigentes escolares, que são sintomáticos de uma crise no moral dos profissionais. Ele fornece alguns dados que mostram por que também há preocupações crescentes sobre o bem-estar dos alunos. Baseia-se em importantes documentos governamentais e de pesquisa e em pontos de vista dos principais interessados para mostrar por que o sistema atual é amplamente visto como fragmentado, sem direção, com desempenho insatisfatório, e que ele aprofunda a desigualdade social em vez de aliviá-la. A seção referente ao Brasil descreve os desafios e as forças dos sistemas educacionais e a importância de investir na profissão docente. 


\section{Resultados de estudantes do Reino Unido em comparação a outros países da Organização para a Cooperação e Desenvolvimento Econômico (OCDE)}

A Inglaterra tem um sistema educacional diferente daqueles que operam autonomamente no País de Gales, Escócia e Irlanda do Norte, as outras três partes do Reino Unido. Com mais de 84\% da população do Reino Unido, a Inglaterra é de longe o maior país dentro da união. Embora o Programa Internacional para Avaliação de Alunos (PISA) identifique agora variações nos resultados dos quatro países, os resultados para jovens de 15/16 anos geralmente baseiam-se naqueles de todo o Reino Unido.

As escolas

públicas são

responsáveis

por quase todos

os alunos na

Inglaterra

Apesar de uma série de políticas destinadas a melhorar o desempenho dos alunos na última década - que tiveram um impacto significativo nas estruturas escolares, na oferta de currículos e nos métodos de avaliação - os resultados medidos pelo PISA, exceto em Ciências, permanecem praticamente inalterados desde 2006 (OECD, 2016). No mais recente ranking da OCDE, de 2015, o Reino Unido ficou em $15^{\circ}$ lugar em ciências, $22^{\circ}$ em leitura e a pontuação em matemática [492 pontos] ficou pouco acima da média da OCDE, 490, ficando em $27^{\circ}$ lugar, atrás do Vietnã e no mesmo patamar de Portugal.

O relatório do PISA indicou que um quinto dos jovens de 15/16 anos no Reino Unido não atingiu o nível 2 em Matemática (o nível de base), indicando que eles eram incapazes de resolver problemas "rotineiramente enfrentados por adultos em suas atividades diárias" (OECD, 2015, p. 4). Não surpreendentemente, a publicação desses resultados atraiu uma cobertura crítica da mídia e debate generalizado sobre por que economias mais pobres e emergentes estavam superando um país que gastava mais em educação do que a média da OCDE. Este é o contexto para uma observação feita pelo Inspetor Escolar Chefe de Sua Majestade em seu Relatório Anual para 2015-2016: "Nosso sistema educacional ainda não é da melhor classe" (OFSTED, 2016, p. 1).

\section{A estrutura da educação pública na Inglaterra}

As escolas públicas são responsáveis por quase todos os alunos na Inglaterra, onde as mensalidades e a maioria dos materiais didáticos são gratuitos, e apenas 7\% frequentam instituições particulares. O Departamento de Normas para Educação (OFSTED), o sistema de fiscalização nacional, considera que os padrões estão subindo nas escolas inglesas, com $90 \%$ das primárias e $79 \%$ das secundárias atualmente consideradas boas ou excelentes (OFSTED, 2017, p. 7).

Apesar dessa avaliação otimista, o atual relatório anual do OFSTED também reconhece profundas desigualdades nos resultados nos níveis socioeconômico e regional. Uma análise detalhada dessas diferenças, publicada no Fórum Central de Educação na Inglaterra: Relatório Anual 2016, concluiu: 
Temos desafios complexos e profundamente arraigados que o sistema deve enfrentar se quiser atuar em um padrão de alta qualidade. Ajudar alunos que sempre foram desfavorecidos a alcançarem seus pares revela-se particularmente difícil - seja no Norte, seja no Sul, seja nas áreas costeiras ou, até mesmo, seja em Londres. As diferenças no desempenho regional significam que os alunos desfavorecidos podem ficar atrás de seus pares em quase meio ano, dependendo de que escola eles frequentam (PERERA, 2016, p. 79).

\section{Diversidade dentro do sistema: escolas religiosas (faith schools), escolas de gramática (grammar schools) e academias (academies)}

Embora a maioria das escolas inglesas ainda siga o Currículo Nacional, está havendo uma diversidade crescente no setor público: $37 \%$ de todas as escolas primárias e 19\% das secundárias são "escolas religiosas", e as porcentagens estão aumentando. Essas escolas, a maioria católicas ou anglicanas, podem selecionar seus alunos por causa da religião (LONG; BOLTON, 2018). Essa situação tem sido normalmente harmoniosa desde sua introdução na Lei de Educação de 1944. Há, no entanto, uma preocupação crescente de que as manifestações religiosas fundamentalistas, ou até extremistas, particularmente do islamismo, impactem a liderança, a cultura, o currículo e a direção de algumas escolas. Esta foi identificada como "uma área de maior preocupação" pela Inspetora Escolar Chefe de Sua Majestade, Amanda Spielman, que em seu atual relatório anual escreveu sobre "aqueles que procuram isolar os jovens do que é convencional, não os preparam para a vida na Grã-Bretanha, ou, pior, ativamente atacam valores britânicos fundamentais" (OFSTED, 2017, p. 15). Ela definiu o contexto em sua introdução:

Muitos pais sentem que é importante que seus filhos sejam educados de acordo com suas próprias crenças culturais e normas comunitárias; e com uma população cada vez mais diversificada, essas normas agora podem diferir consideravelmente. No entanto, o funcionamento efetivo da sociedade britânica depende de alguns valores fundamentais compartilhados, bem como de uma cultura de tolerância e respeito mútuos. Há um número crescente de escolas religiosas conservadoras onde os requisitos legais que estabelecem expectativas de valores compartilhados e tolerância vão de encontro às expectativas da comunidade. As escolas estão, portanto, optando deliberadamente por não atender a esses padrões (OFSTED, 2017 p. 8).

A grande maioria das escolas na Inglaterra não seleciona os alunos por suas habilidades, embora suas admissões geralmente reflitam o perfil socioeconômico da área a que atendem. A maioria, no entanto, distribui ou coloca seus alunos em diferentes disciplinas de acordo com sua aptidão. Um pequeno número [163] de escolas secundárias públicas conhecidas como "escolas de gramática" selecionam por habilidade. As crianças mais pobres estão sub-representadas nessas escolas 
e, como um recente relatório de pesquisa do governo admite, não há evidências de que elas gerem melhores resultados do que aqueles alcançados por crianças com habilidades similares na maioria das escolas não seletivas (BOLTON, 2017).

Eles são amplamente criticados por pesquisadores educacionais e por políticos de todos os âmbitos, inclusive por alguns membros do Partido Conservador, por dividirem socialmente e terem um impacto negativo nos resultados de outras escolas vizinhas. No entanto, em 2017, em um momento de cortes profundos no financiamento escolar geral, o governo alocou 50 milhões de libras [R\$ 256.000.000] para permitir sua expansão. Outros tipos de instituições financiadas pelo Estado incluem escolas "gratuitas", que podem ser criadas por pais, instituições de caridade ou empresas, e Faculdades Técnicas Universitárias para alunos de 14 a 19 anos, embora os números sejam pequenos atualmente.

\section{As academias foram}

promovidas como

caminho para a elevação de padrões
O Governo tem promovido fortemente e, em algumas circunstâncias, imposto legalmente uma mudança na responsabilidade geral pelas escolas, afastando-a de autoridades locais, que são conselhos distritais ou de condados, eleitos por suas comunidades, que têm funções administrativas, de supervisão e de alocação de recursos para manutenção das escolas na sua jurisdição. Em seu lugar, entram cadeias de academias financiadas pelo Estado ou os fundos multiacadêmicos [multi-academy trusts - MATs], que são independentes de qualquer controle democrático local e sobre os quais o escrutínio financeiro está se mostrando problemático (EDUCATION FUNDING AGENCY, 2017). É raro que se passe uma semana sem um escândalo sobre salários excessivos pagos a líderes de MATs ou sobre apropriação indébita de fundos de academia?.

Essas mudanças representam um enfraquecimento das estruturas do governo local e a fragmentação dos fluxos de responsabilização. Antes de 2000, não havia academias na Inglaterra. Até 2018, embora a maioria das escolas primárias permaneçam sob jurisdição de autoridades locais, esse é o caso de menos de um terço das secundárias. O argumento em favor do "processo de academização" é baseado em duas premissas. Em primeiro lugar, que livres do controle de autoridades locais, líderes escolares teriam maior liberdade na tomada de decisões. Quaisquer liberdades adicionais putativas foram nominais. Líderes de escolas públicas na Inglaterra, academias ou não, já possuem os mais altos níveis de autonomia registrados na Pesquisa Internacional de Ensino e Aprendizagem (Teaching and Learning International Survey - TALIS) da OCDE. A análise governamental da pesquisa TALIS concluiu que demonstrava "uma imagem gráfica do alto grau de autonomia escolar na Inglaterra, tanto em termos absolutos quanto em relação a muitos outros países" (GREAT BRITAIN, 2014b, p. 41). Em segundo lugar, e o mais importante, as academias foram promovidas como caminho para a elevação de padrões. No entanto, uma série de investigações mostrou que isso não aconteceu. Uma recente publicação sobre academias pelo Comitê de Educação da House of Commons, que 
analisou esses resultados, observou que eles demonstraram "um quadro misto" em relação ao desempenho geral. O Comitê estava preocupado com o fato de que "um número significativo de MATs não está melhorando ano a ano e constantemente aparecem na parte inferior das tabelas classificativas" e concluiu, citando diretamente um dos relatórios que havia consultado, "está bem claro que elas não são uma solução direta para elevar os padrões" (GREAT BRITAIN, 2017b, p. 25).

\section{Liderança e gerenciamento dentro das escolas}

Órgãos de liderança próprios, compostos por pelo menos sete lideranças, incluindo pais, que são eleitos ou indicados para o cargo por períodos fixos, supervisionam todas as escolas mantidas por uma autoridade local na Inglaterra. Conselhos de Administração ou Diretores supervisionam academias. Nas escolas de caráter religioso, a diocese local ou a fundação respectiva devem nomear a maioria dos líderes ou diretores. Órgãos de Liderança e Conselhos de Diretores examinam regularmente o currículo, o progresso, a segurança e o comportamento dos alunos, o orçamento anual e os preparativos para o quadro de pessoal e a condição das instalações de suas escolas. Eles nomeiam novos diretores, estabelecem e revisam metas anuais e podem estar envolvidos em admissões de alunos e outras nomeações de pessoal. Enquanto os Órgãos de Liderança fazem a supervisão estratégica, eles confiam o funcionamento cotidiano das escolas a professores-supervisores e suas equipes. Nos regulamentos está explícito que, embora lideranças e diretores devam responsabilizar rigorosamente as equipes de administração, devem fazê-lo em um espírito de "amizade crítica" e sem interferir ou atrapalhar o amplo papel dos líderes escolares em dar continuidade ao seu trabalho.

Embora a composição dos Órgãos de Liderança ou Conselhos de Diretores tenha reduzido de tamanho nos últimos anos, as demandas sobre eles aumentam constantemente. As pessoas esperam que atualizem seus conhecimentos por meio de treinamento regular, participem de reuniões noturnas ao longo do ano, estejam familiarizadas com sistemas complexos para medir o progresso e o aproveitamento do aluno e mantenham-se informados sobre as constantes revoltas contra o currículo. As inspeções do OFSTED monitoram e avaliam seu desempenho, e os julgamentos sobre sua eficácia são classificados e tornados públicos. Devido a essas pressões sobre as lideranças, cujo papel é não remunerado e voluntário, o recrutamento tem sido cada vez mais difícil. Em sua mais recente pesquisa, a Associação Nacional de Governança (National Governance Association) reportou que mais da metade de todos os entrevistados relataram não conseguir preencher vagas de liderança em suas escolas (NATIONAL GOVERNANCE ASSOCIATION, 2017).

A profissão docente na Inglaterra tem uma trajetória piramidal clara referente à progressão na carreira. Uma escola secundária com cerca de mil alunos, por exemplo, normalmente tem um diretor, dois vice-diretores e dois ou três diretores assistentes dentro de uma equipe de liderança de cinco ou seis pessoas. As funções de líder 
intermediário geralmente incluem responsabilidade pela qualidade do ensino e dos resultados dos alunos dentro de um departamento acadêmico ou o progresso e o bem-estar dos alunos em uma faixa etária específica. Escolas com cargos disponíveis geralmente anunciam as vagas nacionalmente e a promoção se baseia no mérito por meio de processos de entrevista, nos quais regras estritas se aplicam em relação à transparência e à igualdade de oportunidades. O pagamento e as responsabilidades aumentam à medida que os professores avançam nas classificações com salários acima de $£ 100.000$ [R\$ 500.000,00] por ano, agora comuns para diretores de escolas secundárias. Em relação ao seu status na sociedade, o Índice Internacional de Status de Professores da Varkey GEMS classificou professores na Inglaterra no nível intermediário, enquanto diretores ficaram em primeiro lugar (DOLTON; MARCENARO-GUTIERREZ, 2013).

\section{Avaliação do currículo secundário e desafios emergentes}

A mudança mais significativa desde a Lei de Educação Butler de 1944, que moldou a base da educação pública do pós-guerra na Inglaterra, ocorreu em um período de cinco anos de 1988 a 1992. Os três elementos centrais da provisão atual foram o Currículo Nacional (National Curriculum - 1988), Exames Nacionais (National Testing - 1991) e o OFSTED (1992). Essa transformação de um sistema que, por mais de quarenta anos, foi regulamentado de forma leve, para um no qual o conteúdo do currículo, o aproveitamento dos alunos e a qualidade do ensino e da liderança escolar seriam rigorosamente avaliados, representou um profundo choque cultural para muitos na profissão. Desde então, governos sucessivos estão rapidamente aumentando uma série de adaptações à estrutura, ao conteúdo e à avaliação do sistema educacional público. Muitas vezes abruptas e com pouca consulta, essas mudanças ainda não viram os benefícios obtidos em jurisdições educacionais mais bem-sucedidas, como as da Finlândia e Holanda, onde um amplo consenso entre partidos políticos e profissionais da educação viu melhorias duradouras em resultados de aprendizagem².

As crianças na Inglaterra iniciam sua educação por volta dos 4 anos e a provisão pública continua até os 18 anos. O Sure Start, um programa governamental lançado em 1998, tem direcionado recursos adicionais para famílias carentes, fornecendo mais de quatro mil centros comunitários para doações e desenvolvimento, oferecendo cuidados infantis, educação inicial, saúde e apoio familiar. Apesar das evidências substanciais de que essa iniciativa levou a melhorias muito significativas no progresso e no bem-estar dos bebês mais pobres na Inglaterra (SAMMONS, 2015), os recentes cortes no financiamento levaram ao fechamento de um quarto desses centros, e os restantes tiveram que restringir suas provisões.

Na sequência da provisão mista para crianças desde o nascimento até os 5 anos, conhecida como "Early Years Foundation Stage", a trajetória de aprendizado dos estudantes ingleses é dividida em mais cinco etapas, duas das quais terminam com exames nacionais. $\mathrm{O}$ quadro a seguir descreve a estrutura atual: 
Quadro 1 - Trajetória de aprendizado de estudantes ingleses

\begin{tabular}{|c|c|c|c|}
\hline Idade & Ano & Estágio-chave [EC] & Avaliação \\
\hline 3 a 4 & Creche & Anos iniciais & Introdução de uma avaliação de base de 2020. \\
\hline \multirow[t]{2}{*}{4 a 5} & Recepção & Anos iniciais & \\
\hline & & Primário [EC1/2] & \\
\hline 5 a 6 & Ano 1 & Estágio-chave 1 & Teste de seleção fonética \\
\hline 6 a 7 & Ano 2 & Estágio-chave 1 & \\
\hline 7 a 8 & Ano 3 & Estágio-chave 2 & \\
\hline 8 a 9 & Ano 4 & Estágio-chave 2 & \\
\hline 9 a 10 & Ano 5 & Estágio-chave 2 & \\
\hline \multirow[t]{2}{*}{10 a 11} & Ano 6 & Estágio-chave 2 & $\begin{array}{l}\text { Fim dos Exames Nacionais do EC2 e avaliações de } \\
\text { professores para Inglês, Matemática, e avaliações } \\
\text { moderadas de professores em Ciências. Estes } \\
\text { resultados são usados como base para medir o } \\
\text { progresso que os estudantes tiveram ao final do EC4. }\end{array}$ \\
\hline & & Secundária [EC3/4] & $\begin{array}{l}\text { A maioria das crianças são transferidas de uma } \\
\text { escola primária para uma secundária aos } 11 \text { anos. }\end{array}$ \\
\hline 11 a 12 & Ano 7 & Estágio-chave 3 & \\
\hline 12 a 13 & Ano 8 & Estágio-chave 3 & \\
\hline 13 a 14 & Ano 9 & Estágio-chave 3 & \\
\hline 14 a 15 & Ano 10 & Estágio-chave 4 & \\
\hline \multirow[t]{2}{*}{15 a 16} & Ano 11 & Estágio-chave 4 & $\begin{array}{l}\text { Exames Nacionais: a maioria dos alunos faz os } \\
\text { GCSEs ou outras qualificações nacionais. }\end{array}$ \\
\hline & & Depois dos 16 & $\begin{array}{l}\text { Algumas escolas têm provisões para depois dos } 16 \text {. } \\
\text { Muitos alunos seguem para escolas pós-16. }\end{array}$ \\
\hline $16-18$ & & & $\begin{array}{l}\text { Jovens seguem diferentes cursos acadêmicos ou } \\
\text { vocacionais. }\end{array}$ \\
\hline
\end{tabular}

Fonte: Elaborado pelo autor.

O Estágio-chave [EC2] mais longo dura quatro anos e a transferência para escolas secundárias ocorre quando as crianças têm 11 anos. As avaliações no final do EC2 têm base em testes nacionais de Inglês e Matemática, bem como avaliações moderadas de professores. Esses resultados são a base para medir o desempenho acadêmico das crianças durante todo o ensino médio. Equipes de líderes escolares, órgãos diretores e o Departamento de Educação monitoram de perto o progresso não apenas das crianças individualmente, mas também subgrupos de alunos identificados por suas realizações anteriores, desvantagens sociais, gênero e etnia.

Aos 16 anos, quase todos os jovens prestam o exame nacional do Certificado Geral de Ensino Secundário (General Certificate of Secondary Education - GCSE). Chegar a um consenso sobre a forma mais justa e eficaz de avaliar o progresso e as con- 
quistas de alunos há muito é um dos aspectos mais complicados da educação pública na Inglaterra. Nos últimos dois anos, houve uma revisão radical de um sistema que havia previamente colocado um mínimo de cinco aprovações no GCSE com as notas mais altas de $\mathrm{A}$ a $\mathrm{C}$, incluindo em inglês e matemática, como um padrão nacional para, ou além do qual, os alunos deveriam almejar. O Governo também baseia o desempenho das escolas no percentual da faixa etária do Ano 11 que alcançou ou superou essa meta. A importância fundamental de alcançar pelo menos uma nota C, especialmente em Inglês e Matemática, levou muitas escolas a concentrarem seus esforços e recursos em um grupo relativamente pequeno de estudantes que estavam no nível D/C, prejudicando crianças menos capazes ou com melhor desempenho. Ainda mais problemática, no entanto, foi a óbvia injustiça de um sistema que comparava escolas de áreas pobres, que tinham uma entrada significativa de alunos desfavorecidos com baixo nível de conquistas prévias, a áreas prósperas, algumas das quais tinham admissões baseadas em seleção acadêmica. A inadequação desse modelo de avaliação levou a um novo sistema, o Progress 8, introduzido em 2016.

O Progress 8 tem a intenção de ser um método mais justo de avaliação do progresso dos alunos, bem como de garantir que todos eles tenham acesso a um currículo amplo. A partir de oito resultados do GCSE, ele mede o desempenho dos alunos em seu progresso e suas conquistas. O novo sistema substituiu o intervalo de notas da letra A a G por outro baseado em números ${ }^{3}$. Esse novo sistema dá grande peso ao Inglês e à Matemática, mas também especifica duas outras áreas para avaliação. Em um deles, conhecido como o Bacharelado em Inglês, os alunos devem fazer três testes de uma série de disciplinas que abrangem Ciências, História, Geografia, línguas estrangeiras e ciência da computação. No outro, eles fazem outros três testes de uma lista de qualificações acadêmicas, artísticas ou vocacionais aprovadas: ao todo, oito matérias são avaliadas.

O Governo baseia cada progresso escolar feito por todos os alunos em sua faixa etária de 16 anos nos resultados do teste EC2 que fizeram quando tinham 11 anos, resultados da média nacional para alunos com uma posição acadêmica similar. A pontuação média do Progress 8 para todos os alunos em nível nacional é zero. A pontuação Progress 8 de cada escola geralmente fica entre -1 ou +1 . Uma pontuação de +1 significa que, em média, cada aluno está atingindo uma nota mais alta em cada qualificação do que alunos similares em todo o país e, na mesma medida, uma pontuação de - 1 significa que os alunos têm um desempenho abaixo da média. Uma escola com pontuação de $+0,5$ ou superior apresenta um desempenho bem acima da média. O padrão mínimo aceitável pelo governo para as escolas é uma pontuação geral de -0,5. Qualquer pontuação abaixo disso desencadeia um intenso escrutínio da OFSTED.

O site oficial do governo - <https://www.compare-school-performance.service.gov.uk> - apresenta relatórios sobre uma série de indicadores de progresso e aproveitamento em todas as escolas do país. A Figura 1 a seguir mostra o desempenho de uma escola secundária no Noroeste da Inglaterra em 2017. 
Figura 1 - Desempenho de uma escola secundária no Noroeste da Inglaterra em 2017

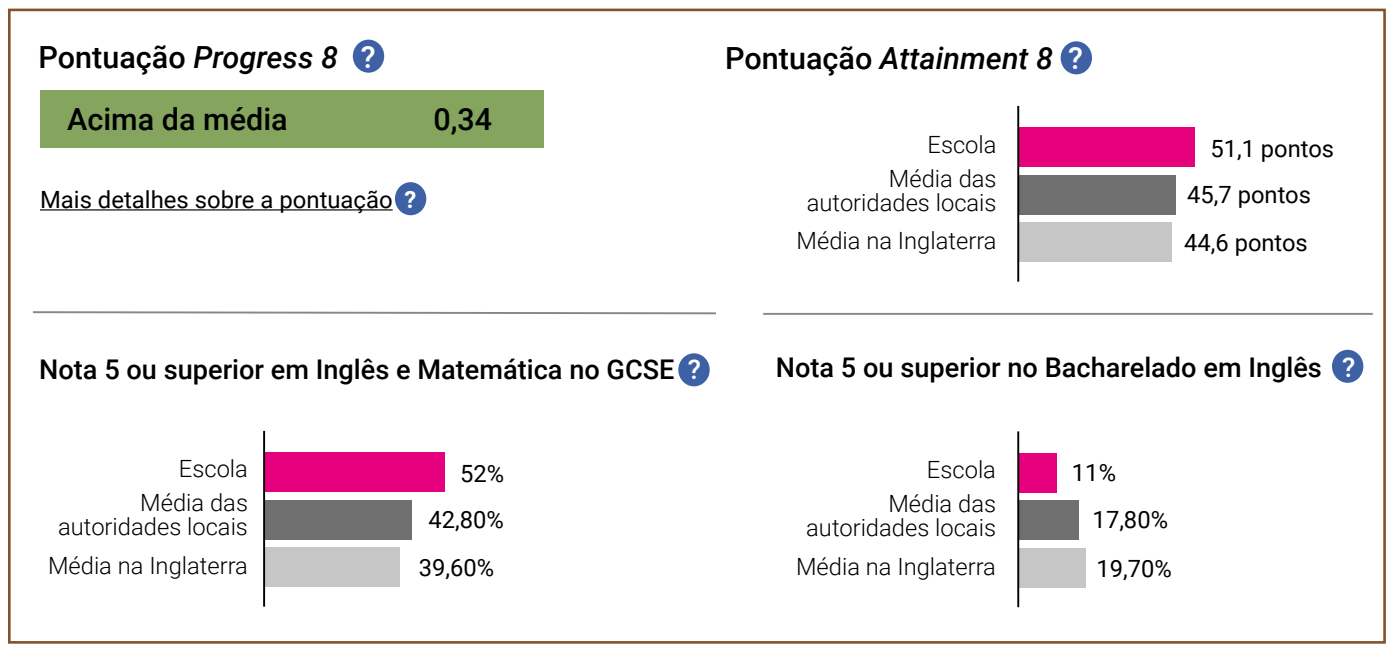

Fonte: Great Britain (2018a).

A primeira tabela, uma pontuação do Progress 8 codificada por cor (neste caso, verde, que indica "acima da média"), oferece um retrato de como os alunos na escola estão progredindo dentro de uma estrutura nacional mais ampla. A seguir, uma pontuação Attainment 8 mostra os resultados dos alunos em comparação local e nacional. O terceiro gráfico identifica a porcentagem de alunos que atingem uma Nota 5 ou superior em Inglês e Matemática. A quarta mostra a porcentagem de estudantes que obtêm o Bacharelado em Inglês (EBacc), ou seja, aqueles que têm notas mais altas em Inglês, Matemática, Ciências, Linguagem e História ou Geografia, e a porcentagem de alunos inscritos para essa combinação.

Apesar de o Progress 8 ser uma avaliação mais justa, mesmo que mais complicada do que seu antecessor, ele ainda é problemático. De acordo com uma pesquisa do próprio governo, mais de $80 \%$ dos pais ainda não estão conscientes dessa nova forma de avaliação (PANAYIOTOU et al., 2017, p. 9). Há uma crítica generalizada de que ele marginalizou disciplinas como Música e Arte. Ele não considera a privação e, portanto, estigmatiza escolas que atendem crianças desfavorecidas (COUGHLAN, 2018). Isso fica evidente nas estatísticas, estudantes que, por diferentes razões, incluindo insatisfação, exclusão social ou questões de saúde, não comparecem para fazer seus exames. Escolas em áreas carentes geralmente têm uma porcentagem maior desses jovens. A pontuação nula dada aos alunos ausentes, incorporada ao resultado geral do Progress 8 para essas escolas, tem um impacto deformador, que disfarça o progresso positivo alcançado pela maioria dos alunos da faixa etária (ALLEN, 2017).

Outra preocupação diz respeito ao Bacharelado em Inglês. O Governo está encorajando sua mais ampla aceitação possível, acreditando que ofereceria a opção mais ampla e desafiadora de currículo. Para demonstrar o comprometimento de cada escola com esse modelo, ele publica não apenas a porcentagem de alunos 
que atingem esse percentual, mas também a porcentagem que se inscreveu para o curso. Se os alunos não aceitarem a opção, os pontos acumulados são reduzidos significativamente. Isso, por sua vez, afeta a pontuação Attainment 8 alcançada pela Escola. Apesar da meta do governo de uma adesão de 90\% pelos estudantes, o progresso em relação a isso tem sido lento. Em 2016, 40\% dos alunos se inscreveram para o EBacc, mas apenas 25\% foram aprovados (LONG; BOLTON, 2017).

Existe uma opinião forte dentro e além da profissão docente, no entanto, de que o EBacc é inadequado para muitos estudantes que se beneficiariam de um caminho mais técnico e baseado em habilidades. O Documento Informativo da House of Commons sobre o assunto citou o então Inspetor Escolar Chefe, Sir Michael Wilshaw, que disse que poderia "imaginar que há jovens que seriam mais adequados para o Inglês, Matemática e Ciências e uma série de disciplinas vocacionais” (LONG; BOLTON, 2017).

\section{Existe uma}

preocupação

crescente de que

o fraco histórico

da educação

profissional na

Inglaterra possa

custar caro ao país
O Secretário-Geral da Associação das Lideranças de Escolas e Colégios também criticou o "enfoque acadêmico restrito", afirmando que tem um efeito restritivo na capacidade das escolas de adaptar a educação a alunos individualmente (LONG; BOLTON, 2017, p. 13). Seu impacto sufocante nas opções alternativas de currículo é demonstrado claramente no declínio acentuado do percentual de alunos prestando exames em Design e Tecnologia: caiu de 42\% em 2010 para 29\% em 2016 (LONG; BOLTON, 2017, p. 23). Existe uma preocupação crescente de que o fraco histórico da educação profissional na Inglaterra possa custar caro ao país. O modelo curricular nacional está cada vez mais fora de sintonia com as características e necessidades em rápida evolução de uma economia moderna. O Brexit apresenta um desafio ainda maior, uma vez que desencadeou um êxodo de trabalhadores qualificados da Europa Oriental e de outros lugares de empregos que agora precisam ser preenchidos pela população nativa. O Governo publicou recentemente documentos sobre como reforçar o ensino profissional e aumentar o nível de qualificação profissional extremamente baixo após os 16 anos (TECHNICAL..., 2016). No entanto, no nível secundário, a oferta de cursos com foco vocacional continua a diminuir.

As preocupações com a fraca oferta vocacional para alunos do ensino secundário refletem um desconforto mais profundo sobre a atual direção e propósito da educação na Inglaterra. Em um discurso para diretores em junho de 2014, Michael Cladingbowl, que era Diretor Nacional de Escolas da OFSTED, argumentou que havia chegado a hora de revisitar as prioridades que moldaram o Currículo Nacional desde sua introdução em 1985. Ele perguntou qual era o objetivo da educação e se ainda era essencial manter um currículo "amplo e equilibrado" em todas as escolas se isso não atendia às necessidades específicas de cada aluno. Ele acreditava que todas as discussões nacionais substanciais sobre o currículo haviam efetivamente secado. 0 foco intenso das escolas nos resultados dos exames era uma das razões pelas quais 
esse debate mais amplo não estava ocorrendo (CLADINGBOWL, 2014). A perspectiva de uma séria conversa nacional colocada por esse discurso, por mais tentadora que possa ter soado para o público, não foi realizada. Muitas das frequentes mudanças e iniciativas do Departamento de Educação, como financiamento adicional para escolas seletivas, têm sido politicamente partidárias, com poucas evidências de consultas substanciais ou esforços para alcançar um consenso nacional.

\section{OFSTED}

O compromisso profundo sentido por professores e líderes de escolas para apoiar o progresso e a conquista dos estudantes sob seus cuidados é, sem dúvida, um poderoso motivador para sua preocupação constante com os resultados acadêmicos: outro fator, no entanto, é o veredito público do OFSTED sobre seu desempenho.

Exceto por escolas que demonstram alto desempenho de forma consistente, que agora são raramente visitadas, as Inspeções OFSTED geralmente acontecem a cada três ou quatro anos. As equipes de inspeção passam normalmente dois dias examinando não só a liderança, o currículo, os processos de avaliação e as conquistas, o progresso e o comportamento dos alunos, mas também

Em termos de classe e etnia, meninos brancos desfavorecidos têm sido o grupo de estudantes com pior desempenho na Inglaterra áreas como segurança do local, medidas de proteção infantil, esforços para evitar a radicalização e a promoção dos "valores britânicos" (GREAT BRITAIN, 2014a; OFSTED, 2018).

As escolas são julgadas como estando em uma de quatro categorias: 1 é "Excelente", 2 é "Bom", 3 é "Precisa Melhorar" e 4 é "Inadequado" ou, se a liderança da escola é percebida como não tendo capacidade de melhorar, como necessitando de "Medidas Especiais". Os diretores cujas habilidades de liderança necessitam de melhorias ou são inadequadas muitas vezes percebem que suas posições se tornam muito vulneráveis, e renúncias ou demissões são comuns.

Na última década, em termos de classe e etnia, meninos brancos desfavorecidos têm sido o grupo de estudantes com pior desempenho na Inglaterra, com menos de um quarto deles alcançando padrões nacionais de referência aos 16 anos de idade (KIRBY; CULLINANE, 2016). Estudantes de minorias étnicas na Inglaterra, de qualquer classe, têm um desempenho melhor do que os adolescentes brancos pobres. Evidências estatísticas de que escolas que atendem a comunidades predominantemente brancas são cinco vezes mais propensas a serem reprovadas do que aquelas que atendem áreas afluentes têm, cada vez mais, abalado a confiança na metodologia do OFSTED (HUTCHINSON, 2016; TIERNEY, 2018) e ganhado espaço na mídia nacional (ROBERTS, 2018). Por mais dedicados que as lideranças escolares, funcionários e estudantes possam ser nessas escolas, muitos acham que nem o Progress 8 nem o Serviço de Inspeção oferecem condições equitativas, resultando em dificuldade crescente para recrutar funcionários e lideranças escolares (GREAT BRITAIN, 2017d, p. 46-47). 


\section{Recrutamento e retenção de lideranças escolares e equipe docente}

A alegação do OFSTED de que ele tem sido uma alavanca para melhorar os padrões nas escolas é desafiada pelo aumento das dificuldades em reter e recrutar professores e lideranças escolares. Os professores do ensino médio na Inglaterra trabalham significativamente mais horas do que a média registrada nos países da OCDE (FOSTER, 2018, p. 33), e os números dos que deixam a profissão aumentam a cada ano.

O mais recente relatório do Departamento Nacional de Auditoria observou: "O Departamento de Educação não consegue demonstrar que seus esforços para melhorar a retenção e a qualidade dos professores estão tendo um impacto positivo". Além disso, citou como exemplo os quase 35 mil professores (mais de $8 \%$ da força de trabalho qualificada), que em 2016, abandonaram a profissão por outras razões que não a aposentadoria (GREAT BRITAIN, 2017c). Em 2017, 40\% dos que haviam começado uma carreira docente em 2007 haviam se demitido (FOSTER, 2018, p. 10).

Apesar dos altos salários de muitas lideranças escolares da Inglaterra, os Órgãos Diretores estão tendo dificuldades para fazer nomeações. Em sua pesquisa mais recente, a Associação Nacional de Governança informou que mais de um terço dos mais de 5.000 correspondentes tinham tido dificuldade em atrair bons candidatos para liderar suas escolas (NATIONAL GOVERNANCE ASSOCIATION, 2017, p. 31). Em uma época em que o número de alunos tem aumentado rapidamente, o Governo tem constantemente falhado em atingir suas metas de recrutamento para a formação de professores e, desde 2012, cresce o déficit de novos profissionais (FOSTER, 2018, p. 4).

Em 2017, em duas áreas de importância crítica no que diz respeito ao investimento na prosperidade futura do país, apenas $66 \%$ das instituições de formação de professores de Tecnologia da Informação e 33\% para Design e Tecnologia foram preenchidos (GREAT BRITAIN, 2017a, p. 6). O Relatório Anual do Inspetor Escolar Chefe para 2015/2016 não economizou na advertência: "O país está enfrentando sérias lacunas de conhecimento e habilidades que ameaçam a competitividade de nossa economia" (OFSTED, 2016, p. 19).

\section{Uma crise no bem-estar, no moral e o declínio na confiança no sistema}

Pesquisas com professores que permanecem na profissão consistentemente indicam um alto grau de descontentamento (NATIONAL EDUCATION SURVEY, 2018). Eles mencionam como fontes de ansiedade a carga de trabalho excessiva, reconhecida com hipocrisia pelo Governo ${ }^{4}$, o intenso escrutínio dos resultados e o medo da próxima inspeção do OFSTED.

A Associação das Lideranças de Escolas e Colégios (ASCL), que representa a maioria das lideranças de escolas secundárias na Inglaterra, critica cada vez mais não 
apenas a deterioração da moral dentro da profissão, mas também o que considera prioridades míopes e falta de direção no sistema educacional da Inglaterra. Seu secretário-geral, em seu discurso anual de 2018, observou como se tornara consciente da "divisão, da fragmentação de um sistema". Contrastando a abordagem educacional visionária que ele havia visto em Xangai, que "olha com ousadia para o futuro", com a inglesa, que se tornara "estreita" e "paroquial", ele descreveu como as lideranças escolares estavam se sentindo "limitadas, podadas por uma linguagem mecanicista de consultoria de gestão com sua conversa sem alma sobre medidas de progresso, responsabilidade, auditorias, dados perdidos e o constante freio do monitoramento. Quando deixamos isso acontecer? Quando paramos de falar sobre crianças e pedagogia, liderança e alegria?" (BARTON, 2018).

O intenso regime de monitoramento e avaliação ordenado pela OFSTED e encorajado em nível individual nas escolas levou a níveis de ansiedade entre os estudantes secundários
Estudantes na Inglaterra, muitos dos quais têm acesso a um currículo inadequado, e todos os quais estão sob intensa pressão para conquistar, à medida que os exames nacionais se tornam cada vez mais exigentes, não estão imunes a esse estresse (GREAT BRITAIN, 2018b, p. 11). Uma pesquisa realizada em 2015 com 1.180 diretores indicou que a maior preocupação era a saúde mental dos alunos (THE KEY, 2015).

Encaminhamentos formais de escolas para apoio externo especializado à saúde mental dos alunos aumentaram um terço nos últimos três anos (NATIONAL SOCIETY FOR THE PREVENTION OF CRUELTY TO CHILDREN, 2015). No entanto, a comissão parlamentar, responsável por examinar o plano do governo para responder a esta crise, informou que "não tem qualquer plano e não considera como prevenir a saúde mental de crianças e adolescentes" (GREAT BRITAIN, 2018b, p. 6).

A educação secundária na Inglaterra está cheia de problemas. Nos últimos 20 anos, houve 12 Secretários de Estado para a Educação diferentes, sete do Partido TrabaIhista e cinco do Partido Conservador. Oito deles ocuparam o cargo por não mais do que um ou dois anos, e cada um deles quis deixar sua marca no serviço de educação público. A falta de consenso político entre as partes e opiniões divergentes dentro delas levaram a duas décadas de descontinuidade e ruptura. O intenso regime de monitoramento e avaliação ordenado pela OFSTED e encorajado em nível individual nas escolas levou a níveis de ansiedade entre os estudantes secundários muito superiores à média da OCDE $($ OECD, 2017) e estão cada vez mais em risco de saúde mental precária. Há uma crise na profissão em termos de recrutamento e retenção, causada principalmente pela carga de trabalho excessiva e pelo estresse causado pelas inspeções do OFSTED e outras formas de monitoramento. Apesar dos altos salários, as vagas para postos de liderança atraem poucos candidatos. Há variações muito significativas, regionalmente e socioeconomicamente, no progresso e nas conquistas dos jovens de 16 anos, sendo os meninos brancos da classe trabalhadora os mais mal-atendidos de todos, com resultados atrás daqueles de 
qualquer outro grupo. Sir Michael Wilshaw, que foi Inspetor Escolar Chefe de Sua Majestade de 2012 a 2016, foi franco em seu julgamento televisionado em um Festival de Educação realizado em junho de 2018 :

É um sistema medíocre. Somos medíocres e é bobagem afirmar o contrário. Se não, estaríamos muito acima da tabela classificativa do PISA, estaríamos com as Coreias do Sul e com os Xangais e alguns dos melhores países europeus como a Polônia, por exemplo. Então somos medíocres. Somos medíocres porque não estamos fazendo o suficiente sobre a grande queda do desempenho escolar, que é uma das piores da OECD, composta principalmente por crianças pobres, compostas principalmente por crianças brancas britânicas de baixa renda (WHITTAKER, 2018).

Em milhares de escolas em toda a Inglaterra, professores dedicados e talentosos liderados por diretores corajosos e altruístas estão fazendo um excelente trabalho. Eles estão inspirando seus alunos, ajudando-os a progredir e conquistar e, ao fazê-lo, estão transformando suas vidas. Eles fazem isso apesar do que Toby Greany e Rob Higham, pesquisadores do Instituto de Educação da University College London, descreveram como "a infindável rotatividade de novas políticas" de sucessivos governos em um sistema que "como um todo está se tornando mais fragmentado e menos equitativo" (GREANY; HIGHAM, 2018).

Não há uma opinião unificada sobre a educação pública na Inglaterra. Não existe um roteiro para preparar os jovens para os enormes desafios que enfrentarão no futuro. Em seu último relatório anual, Sir Michael Wilshaw escreveu: "Como nação, estamos numa encruzilhada. Podemos intervir para injetar no sistema a visão, as habilidades e a energia necessárias, ou podemos nos contentar com o status quo e as consequências desse fracasso" (OFSTED, 2016, p. 17). Quem deve ser incluído no "nós", que propósito e prioridades devem moldar a "intervenção" e quais valores devem formar o núcleo dessa "visão" são questões que estão no cerne do desafio que confronta todas as partes interessadas no futuro da educação secundária na Inglaterra.

\section{Brasil e Inglaterra: alguns desafios e pontos fortes de cada um dos sistemas educacionais}

Quais são as ideias que uma comparação dos sistemas de educação secundária do Brasil e da Inglaterra oferece? Existem muitas áreas em que a Inglaterra demonstra boas práticas. O OFSTED julgou que a qualidade do ensino e da liderança escolar é geralmente boa. Dentro da profissão docente, há rotas claras para progressão na carreira e promoção baseada em mérito. As lideranças escolares priorizam a meIhoria da qualidade de ensino e o apoio à aprendizagem, em vez de se concentrarem em tarefas administrativas. Suas comunidades os respeitam e os salários são bons para padrões internacionais e ingleses. As estruturas e processos, que garantem a segurança e a proteção dos alunos nas escolas públicas, são altamente eficazes e rigorosamente submetidos a monitoramento externo. 
Recursos adicionais, ainda que limitados, são fornecidos para alunos com necessidades especiais ou que são desfavorecidos, e nenhuma criança é impedida de progredir com a faixa etária por estar abaixo do esperado. Embora nos últimos anos os orçamentos das escolas tenham sido reduzidos, houve anteriormente um período significativo de investimento em edifícios e recursos escolares. O "período integral" é padrão. Tais características são, no entanto, típicas de qualquer país europeu rico.

Por outro lado, o atual modelo curricular inglês tem um desempenho inferior em relação aos seus pares internacionais; é rígido e mal adaptado, e há uma crise na oferta e no moral dos professores. Não houve nenhuma tentativa de desenvolver por consenso qualquer clareza de propósito e muito menos qualquer visão de futuro para a educação pública na Inglaterra. Uma sucessão de ministros da educação, a maioria dos quais ocupou o cargo por pouco tempo, mexeu com o currículo, com formatos de avaliação e com estruturas como academias, escolas de gramática e livres. Pesquisadores, cada vez mais, demonstram o impacto negativo que isso teve ao longo do tempo na equidade e coesão social.

O que, por sua vez, a Inglaterra pode aprender com o Brasil? Não há dúvida de que o país enfrenta uma série de desafios, incluindo altos níveis de insatisfação, taxas de evasão e absentismo entre os estudantes, baixo status e remuneração da profissão, e falta de investimento em infraestrutura educacional, agravada pelo limite de gastos do Governo Federal. Uma porcentagem maior de famílias brasileiras afluentes e instruídas envia seus filhos para escolas particulares do que na Inglaterra, o que enfraquece a participação da classe média no sistema público de ensino.

Embora tenha havido ganhos impressionantes na avaliação da educação pública e no aumento dos níveis de alfabetização e habilidades matemáticas desde a década de 1980, em escala internacional o Brasil ainda apresenta um desempenho fraco em relação a outros participantes sul-americanos no PISA. No entanto, em nível estadual, a estrutura federativa do Brasil permite respostas criativas aos desafios educacionais, o que não seria possível no sistema inglês, que é altamente centralizado. Isso levou o relativamente pobre estado do Ceará, no Nordeste, por exemplo, a progredir dos baixos índices de desempenho dos estudantes em 2005 para estar entre os cinco estados brasileiros com melhor desempenho em 2015 (OECD, 2018a, p. 92) e oferecer uma possível rota para outras áreas do país, embora essas oportunidades nem sempre sejam aproveitadas (RAISER, 2018).

Em nível nacional, não há nada na Inglaterra comparável ao Plano Nacional de Educação do Brasil, uma visão coerente, inclusiva e imaginativa do que o país esperava fornecer e alcançar para seus cidadãos em um período de dez anos a partir de 2014. O progresso no que diz respeito a atingir suas metas, no entanto, tem sido dolorosamente lento. Em 2017, foi introduzido um projeto de reforma da educação secundária com o objetivo de envolver os alunos com uma nova oferta curricular, na qual a Base Nacional Comum Curricular, com enfoque na alfabetização (português) e habilidades matemáticas, ocupa $60 \%$ do tempo escolar; $40 \%$ é alocado para os estudantes seguirem as opções vocacionais ou acadêmicas. Isso tem se provado 
um desenvolvimento profundamente controverso, com aqueles que argumentam que dará maior relevância e flexibilidade contestados por outros que acreditam que irá aprofundar as desigualdades dentro da sociedade brasileira, e que falha em abordar as causas que levaram um em cada quatro jovens a não completarem o ensino secundário.

O que é inspirador é a resiliência de tantas lideranças de escolas brasileiras, professores e alunos. Eles se recusam a permitir que as restrições e desafios que enfrentam todos os dias sejam uma desculpa para o mau desempenho. Em ambientes de aprendizagem mal equipados e, às vezes, enfrentando condições absurdas, muitos deles estão obtendo resultados notáveis em relação ao progresso e a conquistas, particularmente no caso de alunos desfavorecidos.

Em seu Relatório Anual de 2016, o Inspetor Chefe de Sua Majestade não mediu palavras: "Meu conselho agora ao governo é se preocupar menos com as estruturas e se preocupar mais com a capacidade. Nenhuma estrutura será eficaz se a liderança for fraca ou se não houver pessoas boas suficientes nas salas de aula" (OFSTED, 2016, p. 14).

\section{Considerações finais}

Ótimos professores e líderes escolares inspiradores são essenciais para as oportunidades de vida dos jovens, particularmente os mais descontentes e desfavorecidos; todos os benefícios que se seguem em termos de coesão social e crescimento econômico devem transformá-los. Tudo se resume a isso: o sucesso ou fracasso de qualquer modelo de currículo ou organização escolar depende, em última análise, da qualidade da força de trabalho.

Brasil e Inglaterra enfrentam alguns desafios em comum, mesmo que as razões e contextos para eles sejam diferentes. A profissão docente é de tão baixa estima e ainda é tão mal paga no Brasil que enfrenta dificuldades significativas de recrutamento e retenção, especialmente de profissionais altamente qualificados e ativos.

Na Inglaterra, a carga de trabalho excessiva, a mudança constante e a responsabilização opressiva resultaram em vagas não preenchidas, uma fuga de professores mais jovens, aumento nas aposentadorias precoces e uma relutância em assumir papéis de liderança escolar.

Nesse aspecto, talvez os dois países devam buscar inspiração em outro lugar. Inglaterra e Brasil melhorarão seus resultados atuais aprendendo com os sistemas de educação mais bem-sucedidos do mundo, que colocaram o status, o desenvolvimento profissional e o bem-estar de professores e lideranças escolares no centro de seus planos para o futuro (OECD, 2018b, p. 136, 146). 


\section{Notas}

1Dois exemplos recentes estão disponíveis em <https://www.theguardian.com/education/2017/oct/21/collapsing-wakefield-city-academies-trust-asset-stripped-schools-millions-say-furious-parents> e <https://www.bbc.co.uk/news/education-43155147>.

${ }^{2}$ Lucy Creehan, em seu livro Cleverlands [2016], explorou profundamente as diferenças entre o sistema educacional inglês e as jurisdições com melhor desempenho em relação ao PISA.

${ }^{3}$ As novas notas numeradas vão de 1 a 9 , a notas mais altas sendo 9 . A Nota 4 será a "Média" e a Nota 5 uma "Média Forte". Como este artigo indica <https://www. tes.com/news/gcse-pass-grade-confusion-deepens-ebacc-requires-grade-4-pupils-grade-5-schools>, ainda há confusão generalizada, mesmo entre educadores, quanto ao que significa essa diferença.

${ }^{4}$ A contribuição do Departamento de Educação (DFE) até agora foi produzir um panfleto frente-e-verso e um pôster com conselhos em 24 de fevereiro de 2017, e criar alguns grupos de trabalho e palestras em março de 2018, por um ministro que promete um futuro "sistema de responsabilidade mais simples". <https://www.gov.uk/government/publications/teacher-workload-poster-and-pamphlet> <https://www.gov.uk/ government/publications/reducing-teachers-workload/reducing-teachers-workload>

\section{Referências}

ALLEN, R. Outliers in Progress 8. London: FFT Education Datalab, 20 Jan. 2017. Disponível em: <https://ffteducationdatalab.org.uk/2017/01/outliers-inprogress-8/>. Acesso em: jul. 2018.

BARTON, Geoff. Annual Conference speech. In: ASCL ANNUAL CONFERENCE, 2018, Birmingham. [Annual...]. Leicester: Association of School and College Leaders, 10 Mar. 2018. Disponível em: <https://www.ascl.org.uk/professionaldevelopment/conferences/ascl-annual-conference/geoff-barton-annualconference-2018-speech.html>. Acesso em: jul. 2018.

BOLTON, P. Grammar school statistics. London: House of Commons Library, 10 Mar. 2017. (Briefing paper, n. 1398). Disponível em: <http://researchbriefings.parliament. uk/ResearchBriefing/Summary/SN01398\#fullreport>. Acesso em: jul. 2018.

\section{CLADINGBOWL, Michael. Address to CASH [Cumbrian Association of Secondary Heads] Annual Conference, 2014. London, 26 June 2014.}

COUGHLAN, S. League tables changes 'toxic' for poor white schools. BBC News, Family \& Education, 25 May 2018. Disponível em: <https://www.bbc.co.uk/news/ education-44196645>. Acesso em: jul. 2018. 
DOLTON, P.; MARCENARO-GUTIERREZ, O. Global teacher status index. London:

Varkey GEMS Foundation, Oct. 2013. Disponível em: <https://www.varkeyfoundation. org/media/2787/2013globalteacherstatusindex.pdf>. Acesso em: jul. 2018.

EDUCATION FUNDING AGENCY. Financial management and governance review: Academy Transformation Trust. London, Mar. 2017. Disponível em: <https://www. gov.uk/government/publications/financial-management-and-governance-reviewacademy-transformation-trust>. Acesso em: jul. 2018.

FOSTER, D. Teacher recruitment and retention in England. London: House of Commons Library, 4 June 2018. (Briefing paper, n. 7222). Disponível em: <https://researchbriefings.files.parliament.uk/documents/CBP-7222/CBP-7222. pdf>. Acesso em: jul. 2018.

GREANY, T.; HIGHAM, R. A market-led school system has put finances before needs of pupils. The Guardian, London, 30 June 2018. Disponivel em: <https:// www.theguardian.com/education/2018/jun/30/market-led-education-system-putsfinances-before-pupils>. Acesso em: jul. 2018.

GREAT BRITAIN. Department for Education. Initial teacher training (ITT) census for the academic year 2017 to 2018, England. London, 30 Nov. 2017a. Disponível em: <https://assets.publishing.service.gov.uk/government/uploads/system/uploads/ attachment_data/file/663141/SFR68_2017_Text.pdf>. Acesso em: jul. 2018.

GREAT BRITAIN. Department for Education. Promoting fundamental British values as part of SMSC in schools: departmental advice for maintained schools. London, Nov. 2014a. Disponível em: <https://assets.publishing.service.gov.uk/government/ uploads/system/uploads/attachment_data/file/380595/SMSC_Guidance_ Maintained_Schools.pdf>. Acesso em: jul. 2018.

GREAT BRITAIN. Department for Education. Search for schools in England and colleges to compare. London, [2018a]. Disponível em: <https://www.compareschool-performance.service.gov.uk/>. Acesso em: jul. 2018.

GREAT BRITAIN. Department for Education. Teachers in England's secondary schools: evidence from TALIS 2013: research report. London, June 2014b. Disponível em: <http://dera.ioe.ac.uk/20391/1/RR302_-_TALIS_report_NC.pdf>. Acesso em: jul. 2018.

GREAT BRITAIN. House of Commons. Education Committee. Multi-academy trusts: seventh report of session 2016-17. London, 28 Feb. 2017b. Disponível em: $<$ https://publications.parliament.uk/pa/cm201617/cmselect/cmeduc/204/204. pdf>. Acesso em: jul. 2018. 
GREAT BRITAIN. House of Commons. Education and Health and Social Care Committees. The Government's green paper on mental health: failing a generation. London, 9 May 2018. Disponível em: <https://publications.parliament. uk/pa/cm201719/cmselect/cmhealth/642/642.pdf>. Acesso em: jul. 2018.

GREAT BRITAIN. National Audit Office. Retaining and developing the teaching workforce. London, 12 Sept. 2017c. Disponível em: <https://www.nao.org.uk/pressrelease/retaining-and-developing-the-teaching-workforce/>. Acesso em: jul. 2018.

GREAT BRITAIN. Social Mobility Commission. State of the nation 2017: Social Mobility in Great Britain. London, Nov. 2017d. Disponível em: <https://assets. publishing.service.gov.uk/government/uploads/system/uploads/attachment_ data/file/662744/State_of_the_Nation_2017_-_Social_Mobility_in_Great_Britain. pdf>. Acesso em: jul. 2018.

HUTCHINSON, J. School inspection in England: is there room to improve? London: Educational Policy Institute, Nov. 2016. Disponível em: <https://epi.org. uk/wp-content/uploads/2018/01/school-inspection-in-england-web.pdf>. Acesso em: jul. 2018.

THE KEY. Summer report 2015: school leaders' concerns about pupil wellbeing. London, [2018]. Disponível em: <https://thekeysupport.com/wp-content/ uploads/2018/03/summer_report_2015_school_leaders_concerns_about_pupil_ wellbeing.pdf>. Acesso em: jul. 2018.

KIRBY, P.; CULLINANE, C. Class differences: ethnicity and disadvantage. Research Brief, n. 14, Nov. 2016. Disponível em: <https://www.suttontrust.com/wp-content/ uploads/2016/11/Class-differences-report_References-available-online.pdf>. Acesso em: jul. 2018.

LONG, R.; BOLTON, P. English baccalaureate. London: House of Commons Library, 4 Sept. 2017. (Briefing paper, n. 06045). Disponível em: <https://researchbriefings. parliament.uk/ResearchBriefing/Summary/SN06045>. Acesso em: jul. 2018.

LONG, R.; BOLTON, P. Faith schools: FAQs. London: House of Commons Library, 6 June 2018. (Briefing paper, n. 06972). Disponível em: <https://researchbriefings. parliament.uk/ResearchBriefing/Summary/SN06972>. Acesso em: jul. 2018.

NATIONAL EDUCATION UNION (England). Teachers and workload. London, Mar. 2018. Disponível em: <https://neu.org.uk/file/503/download?token=SFdBXnUa>. Acesso em: jul. 2018. 
NATIONAL GOVERNANCE ASSOCIATION. School governance in 2017: an annual survey. Birmingham, Oct. 2017. <https://www.nga.org.uk/Guidance/Workings-OfThe-Governing-Body/Governance-Tools/School-governance-in-2017-an-annualsurvey-by-NGA.aspx>. Acesso em: jul. 2018.

NATIONAL SOCIETY FOR THE PREVENTION OF CRUELTY TO CHILDREN. School referrals for mental health treatment rise by over a third. London, 14 May 2018. Disponível em: <https://www.nspcc.org.uk/what-we-do/news-opinion/one-thirdincrease-in-school-referrals-for-mental-health-treatment/>. Acesso em: jul. 2018.

OECD. OECD economic surveys: Brazil, 2018. Paris, Feb. 2018a. Disponível em: <http://epge.fgv.br/conferencias/apresentacao-do-relatorio-da-ocde-2018/files/ oecd-economic-surveys-brazil-2018.pdf>. Acesso em: jul. 2018.

OECD. Programme for International Student Assessment. Country note: United Kingdom: results from PISA 2015. Paris, 2016. Disponível em: <https://www.oecd. org/pisa/PISA-2015-United-Kingdom.pdf>. Acesso em: jul. 2018.

OECD. Programme for International Student Assessment. Effective teacher policies: insights from PISA. Paris: OECD Publishing, 2018b. Disponível em: <https://read.oecd-ilibrary.org/education/effective-teacherpolicies_9789264301603-en\#page1>. Acesso em: jul. 2018.

OECD. Programme for International Student Assessment. PISA 2015 results, v. 3: students' well-being. Paris, 19 Apr. 2017. Disponível em: <http://www.oecd.org/ education/pisa-2015-results-volume-iii-9789264273856-en.htm>. Acesso em: jul. 2018.

OFSTED. The annual report of Her Majesty's Chief Inspector of education, children's services and skills 2015/16. Manchester, 2016. Disponível em: <https:// www.gov.uk/government/publications/ofsted-annual-report-201516-educationearly-years-and-skills>. Acesso em: jul. 2018.

OFSTED. The annual report of Her Majesty's Chief Inspector of education, children's services and skills 2016/17. Manchester, 2017. Disponível em: <https:// www.gov.uk/government/publications/ofsted-annual-report-201617-educationchildrens-services-and-skills>. Acesso em: jul. 2018.

OFSTED. School inspection handbook: handbook for inspecting schools in England under section 5 of the Education Act 2005. Manchester, Apr. 2018. Disponível em: <https://assets.publishing.service.gov.uk/government/uploads/ system/uploads/attachment_data/file/699810/School_inspection_handbook_ section_5.pdf>. Acesso em: jul. 2018. 
PANAYIOTOU, S. et al. Omnibus survey of pupils and their parents/carers. London: Department for Education, July 2017. Disponível em: <https://assets.publishing. service.gov.uk/government/uploads/system/uploads/attachment_data/ file/626068/PPC_Omnibus_Wave_2_Report.pdf>. Acesso em: jul. 2018.

PERERA, N. et al. Education in England: annual report 2016. [S.I.]: Centre Forum, 2016. Disponível em: https://epi.org.uk/wp-content/uploads/2018/01/education-inengland-2016-web.compressed.pdf. Acesso em: jul. 2018.

RAISER, M. Brazil can improve education by copying its own successes. [S.I.]: Brookings, 6 Mar. 2018. Disponível em: <https://www.brookings.edu/blog/futuredevelopment/2018/03/06/brazil-can-improve-education-by-copying-its-ownsuccesses/>. Acesso em: jul. 2018.

ROBERTS, J. Is Ofsted fit to judge deprived schools? London: Times Educational Supplement, 16 June 2018. Disponível em: <https://www.tes.com/news/ofsted-fitjudge-deprived-schools>. Acesso em: jul. 2018.

SAMMONS, P. et al. The impact of children's centres: studying the effects of children's centres in promoting better outcomes for young children and their families: evaluation of children's centres in England. London: Department for Education, Dec. 2015. Disponível em: <https://assets.publishing.service.gov.uk/ government/uploads/system/uploads/attachment_data/file/485346/DFE-RR495_ Evaluation_of_children_s_centres_in_England_the_impact_of_children_s_centres. pdf>. Acesso em: jul. 2018.

TECHNICAL education reform: the case for change. London: Department for Business Innovation and Skills: Department for Education, July 2016. Disponível em: <http://dera.ioe.ac.uk/26806/1/Technical_Education_Reform_-_Case_For_ Change.pdf>. Acesso em: jul. 2018.

TIERNEY, S. Graphically exposing Ofsted bias? [London]: LeadingLearner, 12 June 2018. Disponível em: <https://leadinglearner.me/2018/06/12/graphically-exposingofsted-bias/>. Acesso em: jul. 2018.

WHITTAKER, F. 'Not all teachers do their best', and 7 other things Sir Michael Wilshaw said at Festival of Education. Schools Week, 21 June 2018. Disponível em: <https://schoolsweek.co.uk/not-all-teachers-do-their-best-and-7-other-thingssir-michael-wilshaw-said-at-the-festival-of-education/>. Acesso em: jul. 2018. 